\title{
Erratum to: Genome-wide SNP loci reveal novel insights into koala (Phascolarctos cinereus) population variability across its range
}

\author{
Shannon R. Kjeldsen ${ }^{1}$ (D) Kyall R. Zenger ${ }^{1,2} \cdot$ Kellie Leigh $^{3,4} \cdot$ William Ellis $^{5}$. \\ Jennifer Tobey ${ }^{6} \cdot$ David Phalen $^{4} \cdot$ Alistair Melzer $^{7} \cdot$ Sean FitzGibbon ${ }^{5}$. \\ Herman W. Raadsma ${ }^{4}$
}

Published online: 3 November 2015

(C) Springer Science+Business Media Dordrecht 2015

\section{Erratum to: Conserv Genet DOI 10.1007/s10592-015-0784-3}

Unfortunately, in the original publication of the article, the name of the fifth author has been misspelt. The correct name is given in this erratum.

The online version of the original article can be found under doi:10.1007/s10592-015-0784-3.

Shannon R. Kjeldsen

shannon.kjeldsen@jcu.edu.au

1 College of Marine and Environmental Sciences, James Cook University, Building 145, Townsville, QLD 4811, Australia

2 Centre for Sustainable Tropical Fisheries and Aquaculture, James Cook University, Townsville 4811, Australia

3 Science for Wildlife, PO Box 286, Cammeray, NSW 2062, Australia

4 Reprogen-Animal Bioscience Group, Faculty of Veterinary Science, University of Sydney, Private Mail Bag 4003, Narellan, NSW 2570, Australia

5 School of Agriculture and Food Science, The University of Queensland, Brisbane 4072, Australia

6 San Diego Zoo, San Diego, CA 92101, USA

7 School of Medical and Applied Science, CQ University, Rockhampton 4702, Australia 